\title{
Understanding Academic Engagement and Context through Multimodal Data
}

\author{
Runzhi Kong \\ The University of Hong Kong \\ runzhi@hku.hk
}

\author{
Xiao $\mathrm{Hu}$ \\ The University of Hong Kong \\ xiaoxhu@hku.hk
}

\author{
Allen H.K. Yuen \\ The University of Hong Kong \\ hkyuen@hku.hk
}

\begin{abstract}
The Internet has penetrated the life of adolescents and become a new space for learning, socializing and entertainment. Physical exercise and sleep remain crucial for the development of adolescents. However, the influence of these critical contextual factors on learning and life is insufficiently explored, partially due to the difficulty of measuring these factors. To bridge the gap, a semi-automated Day Reconstruction Method was proposed which leverages 24-hour multimodal data collected by smart wristband (Fitbit Versa), paired mobile phone (Red Mi 6), and time management application (RescueTime). A pilot study was conducted to verify the feasibility of this proposed method and is reported in this paper. As academic engagement among adolescents is widely concerned by stakeholders, this pilot study also explores the relationship between the aforementioned contextual factors and academic engagement. With some interesting patterns, revealed, this study contributes to furthering our understanding of how context shapes adolescents' academic engagement using a more objective and nonintrusive method.
\end{abstract}

\section{Introduction}

Academic engagement among adolescents is a widely concerned topic among parents, educators, and other stakeholders, mainly because engagement directly links to desired school behaviors and learning outcomes. Besides general school engagement, in recent years, students' engagement in mathematics (Math) has also gained much attention, given the importance of mathematical thinking and the loss of interest in Math among school students[1].

Tremendous research has been putting effort into investigating the school-home context that influences students' academic engagement[2], [3]. Being inspired by the philosophical concept of lifeworld [4], an adolescents' academic engagement is shaped by a broader context that is not limited to school or family relations. The lifeworld is a dynamic background where we live in, where our thoughts, behaviors and feelings are shaped, and where we make sense of everything we experience. Daily routine, therefore, can be very presentative to a secondary school students' lifeworld.

The permeation of Internet has made being online as a daily routine for adolescent no matter for hedonic or utilitarian purposes. Sleep and physical activities are also intuitively constituting a large part of adolescents' daily routine and critical for the development of adolescents. However, the influence of these critical contextual factors on learning and life is insufficiently explored, partially due to the difficulty of measuring these factors.

To bridge the gap, we propose a new semiautomated method for monitoring and measuring the contextual factors, namely Day Reconstruction Method. It collects multimodal data on a 24-hour basis, through synchronized use of multiple wearable devices and software: a smart wristband (Fitbit Versa), paired a mobile phone (Red Mi 6), and a time management application (RescueTime). This paper reports a pilot study that was conducted to verify the feasibility of this method, in the task of exploring the relationships between contextual factors captured in the lifeworld and academic engagement.

In this pilot study, the lifeworld is operationalized and represented by the 24-hour picture of three factors of an individual, namely 1) internet use, 2) physical activities and 3) sleep. Through the lens of lifeworld, this study aims to understand how these factors shape adolescents' academic engagement. Specifically, the following two research questions (RQs) are addressed:

RQ1. To what extent can contextual factors in adolescents' lifeworld (Internet Use, Physical Activity, Sleep) be captured using the Day Reconstruction Method?

RQ2. To what extent are these contextual factors (Internet Use, Physical Activity, Sleep) related to academic engagement (school engagement and engagement in Math)? 
The remaining of the paper is organized as follows. Section 2 reviews critical concepts related to academic engagement and previous work on these contextual factors (Internet Use, Physical Activity, Sleep) and academic engagement. The proposed method and the pilot study where the method was used are elaborated in Section 3. Section 4 presented the results. Discussions and Conclusions are presented in Section 5. Section 6 concludes the paper and envisions future work.

\section{Literature Review}

\subsection{Academic Engagement}

Defined by Frederic and his colleagues, engagement is a multifaceted concept which consists of overarching but interrelated domains, that is cognitive, affective and behavioral engagement[5]. In other word, how people think, feel and behave defines engagement[6].

Behavioral engagement refers to students' participation, persistence on learning or school activities and positive conduct [7]. Emotional engagement refers to students' emotional reactions to academic activities, subject, teachers, peers or school, such as the sense of belonging [8]. Cognitive engagement address investing sufficient effort, using deep learning strategies, regulate oneself, taking challenges to learn [6], [9]. For example, an individual gets confused on a complex problem but being concentrated and resourceful to solve the puzzle [10].

The fourth dimension, agentic engagement, was put forward by Reeve \&Tseng (2011)[11]. Agentic engagement address that students proactively, intentionally and constructively let teachers know what interests them or raise questions and further change the original instructional flow into what they prefer. For example, a student asked a question during class, and the teacher explained that questions with cases and involves other students in giving in-depth insight.

Engagement has been widely acknowledged as an antidote to students' boredom, declining motivation and learning performance [6], [12], [13]. Engagement is a pervasive term in the field of education because it leads to better academic performance, positive conduct in school [3]. Furthermore, engagement is so crucial due to its malleable nature. Engagement is sensitive and responsive to the context, such as teachers' practices, particularly at the secondary school level [14]. Other than general school engagement, secondary school students are at high risk of declining academic engagement in Math[15]. This declining was found to be associated with students and contextual factors within and beyond classroom[15], such as socioeconomic status, parents.

Not only students' general engagement has gained a lot of attention, but the specific engagement in Math is also important for researchers to investigate. It has been well-documented that a number of students will lose their interest in learning Math during school years[1]. However, this disengagement from Math will reduce students' future opportunities of career development and lost a mathematically thinking approach to understand the world[16].

\subsection{Previous Work on Contextual Factors of Learning}

Sleep plays a critical role in brain and many other physiological functions. Extensive studies have reported the risk of insufficient sleep, including the emotional and behavioral problems[17], cognitive deficit[18] and lower academic performance [19] among adolescents. Not only the sleep duration is essential, even delayed sleep schedule is associated with lower academic grades[20].

Physical exercise yields from zero to medium effect on academic engagement [21] according to a recent meta-analysis study. To explain this relationship, the operationalized indicators from the literature for understanding physical exercise often includes (1) Intensity, (2) Timing (for example, the activity during recess time) (3) Frequency [21]. A very pertinent longitudinal study [22] conducted in Australia shows the relationship between physical activity and three domains of engagement (behavioral, emotional and cognitive) and academic performance among adolescents. The result of this study reveals a strong association with vigorous physical activity and academic engagement is found among boys, but no such association is found in girls.

Internet as an important context for academic engagement is also a controversial issue. Internet use has been associated with lower behavioral engagement among adolescents. Among the problematic internet use behaviors, social networking mainly draws attention, and it reveals the positive association with negative indicators, such as depression [23], sleep problems [24]. Notably, a recent review study reveals that problematic technology use has a significant effect, particularly on adolescents over 14 years old[25]. On another hand, internet use can be beneficial for learning, such as online learning[26]. Internet use is also found to be negatively associated with family conflict, particularly with the purpose of learning [27] and positively associated with higher academic engagement [28]. 
By connecting the nodes among literature, it is evident that sleep, physical exercise, and internet use are dynamic, overarching and interrelated daily events. For example, the literature reveals that sedentary behavior, especially which accompanies with internet use is positively associated with shorter sleep duration [29]. Moreover, it is found using the internet with learning purpose is associated with better sleep and physical exercise [30]. In past studies, the relationship between the above contextual factors and domains of engagement yields inconclusive results across studies. Moreover, to the best of my knowledge, these are few studies that explored how these contextual factors jointly and independently influence secondary students' academic engagement.

\section{Semi-Automated Day Reconstruction Method}

Most existing studies on exploring the relationship between context and academic engagement are based on self-report, observation, interview or administrative data. However, a recent meta-analysis study report that the studies using objective measures result in the large positive association between physical exercise and academic engagement, whereas the studies which employed subjective measures, such as survey, leads to a small positive association[21]. Inspired by the literature, this study aims to use a more objective and continuous method for understanding the context.

Day Reconstruction Method (DRM) has been used among the literature as a technique to construct daily experience [31]. Traditionally, DRM engages participants to recall the episodes in sequence. Each episode consists of variables, such as duration, location, activity. However, using retrospective recall is burdensome for participants. Its validity is also challenged. Therefore, this study proposed a semiautomated tracking method [32], which offers the opportunities to release participants from answering plenty of retrospective questions. Moreover, it enhances the accuracy of the collected data. Meanwhile, it enables researchers to collect momentary data and further draw a holistic picture of participants' daily routine. The design of this semiautomated tracking method is presented in this section.

\subsection{Wearable Devices and Software}

In this method, data are collected via the two interrelated wearable devices: 24/7 Fitbit Versa Watch, paired with mobile phone (Red Mi 6). Smartwatch is used to collect participant's physical activity data and sleep data. The mobile phone is used for participants to respond questionnaires. A total of three questionnaires are distributed via mobile phone during the non-class time to ask questions related to school engagement, engagement in Math and daily Internet usage.

A summary of collected data metrics through smartwatch is presented in table 1. It is noted that in Fitbit smartwatch, the exercise intensity was defined using standard Metabolic equivalents (MET). MET are widely used to represent the intensity and energy expenditure of activities. One MET represents an energy expenditure of one kilocalorie per kilogram of body mass per hour [33]. When MET ranges from 1 to 2.9 , the activity is categorized as lightly active. When MET ranges from 3 to 5.9, the activity is categorized as fairly active. For activities with MET above 5.9, they are categorized as very active [34]. Fitbit shows a good validity in measuring physical activities [35]. It is also shown to be reliable in measuring sleep statues and quality[36].

Table 1. Collected data metrics

\begin{tabular}{ll}
\hline Category & Metrics \\
\hline Exercise & Steps \\
related & Minutes of Sedentary \\
activity & Minutes of Lightly Active \\
& Minutes of Fairly Active \\
& Minutes of Very Active \\
& Activity Calories \\
Sleep related & Minutes Asleep \\
activity & Minutes Awake \\
& Minutes of REM Sleep \\
& Minutes of Light Sleep \\
& Minutes of Deep Sleep \\
\hline REM: rapid eye movement (one phase of sleep stages);
\end{tabular}

Moreover, participants are encouraged to install RescueTime in their own digital devices (including computer or mobile phone). RescueTime (https://www.rescuetime.com) is a time management software which tracks individual digital device usage. This application has been employed in several studies [37] where data were directly retrieved from RescueTime. However, the judgement of positive Internet use and problematic Internet use heavily relies on individual perceptions. Therefore, asking participants to fill out a questionnaire by referring to the data provided by RescueTime could be a better solution than retrieving raw information

\subsection{School Engagement Questionnaire (SEQ)}

The SEQ [6] has been widely used to measure school engagement. For example, one recent study [38] has employed this scale among Hong Kong secondary 
school students with Cronbach's alpha of 0.942. In this study, SEQ is used to assess general engagement towards school from three domains, including behavioral (e.g. I follow the rules at school"), emotional (e.g. "I feel excited by my work at school") and cognitive (e.g. "I study at home even when I don't have a test.") engagement. In total, SEQ consists of 18 items, which takes around fifteen minutes to complete. Each item is rated on a five-point Likert scale.

\subsection{Mathematic Engagement Questionnaire (MEQ)}

MEQ was adopted from the Math and Science Scale [39] and Agentic Engagement Scale [11]. the Math and Science Scale has been used to measure elementary school students' Math engagement in China, which the reliability coefficients of the subscales ranged from .63 to .85 [40]. The Agentic Engagement Scale has been used among university students[41]. MEQ consists of four domains of engagement in Math learning, including cognitive (e.g. "I try to understand my mistakes when getting something wrong"), emotional (e.g. "I enjoy learning new things about Math"), behavioral (e.g. I stay focused in class), and agentic (e.g." I offer suggestions about how to make the class better") engagement. In total, this measure consists of 22 items, which takes around five to ten minutes to answer all the questions. Each item is rated on a five-point Likert scale.

\subsection{Internet Use Questionnaire (IUQ)}

Internet Use Questionnaire (IUQ) is created in this study for understanding adolescents' Internet use. IUQ is consisted of two questions, one question asks about the duration of Internet use ("How many hours did you spend online today?"), the other asks about the duration of productive Internet use ("How many hours did you spend online productively today?"). IUQ takes around one minute to complete.

To improve the objectivity of the IUQ, participants are encouraged to fill out this questionnaire by referring to the data shown on the RescueTime. For participants who choose not to install RescueTime, this questionnaire can be answered based on their perception.

\subsection{Pilot Study}

A pilot study was conducted to verify the feasibility of the proposed method in collecting reliable and valid data, for the task of investigating the relationship between contextual factors and academic engagement of secondary school students' in Hong Kong. The education system in Hong Kong provides six years of high school education from Form 1 to Form 6. Students in this pilot study were in Form 1 and Form 3 (comparable to Grade 7 and Grade 9 students in the U.S. system) in one government secondary school in Hong Kong. Two classes participated, including 32 participants (18 males) from Form 3, and 20 participants $(8$ males $)$ from Form 1. Initially, 52 participants were recruited. After filtering out the missed questionnaires, 39 participants were included in the General Engagement (GE) group, which aimed to understand the relation of context and school engagement. 46 participants were included in the Engagement in Math (EM) group on which the relation of context and academic engagement in Math was explored. The pilot study was conducted between March and April 2019, which lasted for two weeks in total.

After obtaining consent from students, parents and school principal, one day before data collection, a briefing session was held to introduce the project and the rights of participants. It was a dialogue to ensure participants fully understood what would happen in the project, as well as to answer questions or concerns participant might have. At the end of the brief session, devices were distributed to every participant.

During data collection, participants were asked to wear Fitbit Versa and take mobile phone around for 24 hours and seven days. SQE, MEQ and IUQ were translated into traditional Chinese, the native language of the participating students, and were sent through Firebase to the mobile phone. All the questionnaires are distributed during recess time or after school period. On the first day, SEQ, MEQ and IUQ were sent through the mobile phone at one time. Another notification was pushed to the participant who did not answer the questionnaires by the end of the day. From the second day to the last day, the IUQ were pushed to participants on a daily base.

All data analysis was conducted by applying SPSS 25.0. Missing data were estimated using the Expectation Maximization method. Subsequently, descriptive statistics were calculated. Pearson's correlations were used to reveal possible relationships.

\section{Preliminary Findings}

Means, standard deviations (SDs), of the measured metrics of the participants in the GE group and the EM group are displayed in Table 2 .

Alpha coefficient was employed to evaluate the internal consistency of SEQ and MEQ. The result is 
presented in Table 3. The alpha coefficients for the scores derived from the SEQ subscales ranged from 0.694 to 0.811 , indicating acceptable internal reliability. The alpha coefficients for the scores derived from the MEQ subscale ranged from 0.656 to 0.887 , also considered as acceptable.

Table 2. Descriptive characteristics

\begin{tabular}{|c|c|c|}
\hline Characteristics & $\begin{array}{c}\text { GE Group } \\
(\mathrm{N}=39) \\
\text { Mean }(\mathrm{SD}) \\
\end{array}$ & $\begin{array}{c}\text { EM Group } \\
(\mathrm{N}=46) \\
\text { Mean (SD) }\end{array}$ \\
\hline \multicolumn{3}{|c|}{ Engagement in Five-point Likert Scales } \\
\hline $\mathrm{BE}$ & $3.81(.56)$ & $3.82(.70)$ \\
\hline $\mathrm{EE}$ & $3.69(.60)$ & $3.88(.53)$ \\
\hline $\mathrm{CE}$ & $3.29(.70)$ & $3.57(.87)$ \\
\hline $\mathrm{AE}$ & & $2.52(.76)$ \\
\hline \multicolumn{3}{|c|}{ Sleep Stages Minutes per day } \\
\hline Asleep & $406.82(61.78)$ & $402.81(62.73)$ \\
\hline Awake & $57.44(12.97)$ & $57.92(11.44)$ \\
\hline REM Sleep & $97.68(24.51)$ & $97.24(23.73)$ \\
\hline Light Sleep & $256.85(69.99)$ & $256.85(66.11)$ \\
\hline Deep Sleep & $79.75(18.91)$ & $80.52(17.92)$ \\
\hline \multicolumn{3}{|c|}{ Internet Activity Hours per day } \\
\hline Overall & $3.31(2.43)$ & $3.31(2.28)$ \\
\hline Productive & $1.53(1.47)$ & $1.59(1.34)$ \\
\hline \multicolumn{3}{|c|}{ Physical Activity Minutes per day } \\
\hline Sedentary & $866.91(173.60)$ & $860.81(161.75)$ \\
\hline Lightly Active & $193.37(58.16)$ & $191.90(58.40)$ \\
\hline Fairly Active & $25.50(14.76)$ & $25.04(14.560$ \\
\hline Very Active & $19.50(12.21)$ & $19.28(11.84)$ \\
\hline \multicolumn{3}{|c|}{ Other (per day) } \\
\hline Steps & $8169.18(2142.72)$ & $8152.40(2316.05)$ \\
\hline Activity calories & $1164.66(685.78)$ & $1126.21(650.01)$ \\
\hline
\end{tabular}

Table 3. Alpha coefficients of scales

\begin{tabular}{llll}
\hline & Scales & $\begin{array}{l}\text { Number } \\
\text { of items }\end{array}$ & $\begin{array}{l}\text { Cronbach's } \\
\text { Alpha }\end{array}$ \\
\hline SEQ & BE & 5 & 0.694 \\
& EE & 6 & 0.747 \\
MEQ & CE & 7 & 0.811 \\
& BE & 5 & 0.713 \\
& CE & 5 & 0.656 \\
& EE & 4 & 0.887 \\
& AE & 3 & 0.734 \\
\hline
\end{tabular}

$\mathrm{BE}=$ behavioral engagement; $\mathrm{EE}=$ emotional engagement; $\mathrm{CE}=$ cognitive engagement; $\mathrm{AE}=$ agentic engagement;

\subsection{School Engagement}

The correlations between contextual factors and three domains of school engagement (behavioral, emotional, and cognitive) are reported in Table 4. Emotional engagement in school and asleep duration were significantly correlated, $\mathrm{r}=.304, \mathrm{p}=<.05$ in boys. Emotional engagement in school and being sedentary were significantly negatively correlated in girls, $\mathrm{r}=$ $.449, \mathrm{p}<.05$., but not in boys. Emotional engagement in school and light active physical activity were significantly correlated regardless of gender, $r=.445$, $\mathrm{p}<.01$. No significant correlation was found between other contextual factors and the three domains of school engagement.

\subsection{Engagement in Math}

The correlations between contextual factors and four domains (behavioral, emotional, cognitive and agentic) of mathematic engagement are reported in Table 5. Emotional engagement in Math and asleep duration were significantly negatively correlated, $\mathrm{r}=$ $.407, \mathrm{p}<0.5$ among girls. Emotional engagement in Math and REM sleep duration were significantly negatively correlated, $\mathrm{r}=-.428, \mathrm{p}<0.5$ among girls. Steps and cognitive engagement in Math were correlated, $\mathrm{r}=.437, \mathrm{p}<.05$ in boys but not in girls. Agentic engagement in Math and duration of awake were significantly correlated, $r=0.419, p=<0.5$. Agentic engagement in Math and light active physical activities were significantly correlated, $\mathrm{r}=.378, \mathrm{p}<0.1$. Agentic engagement in Math and very active physical activities were significantly correlated, $\mathrm{r}=.351, \mathrm{p}<0.5$. Agentic engagement in Math and calories burnt were significantly correlated, $\mathrm{r}=.543, \mathrm{p}<0.1$. There was no significant correlation found between other contextual factors and four domains of engagement in Math.

Table 4. Pearson correlations between contextual factors and domains of school engagement

\begin{tabular}{|c|c|c|c|c|}
\hline & & $\mathrm{BE}$ & $\mathrm{EE}$ & $\mathrm{CE}$ \\
\hline \multirow[t]{3}{*}{ Asleep } & M & .205 & $.466^{*}$ & .180 \\
\hline & $\mathrm{F}$ & .087 & -.160 & -.300 \\
\hline & All & .077 & .018 & -.157 \\
\hline \multirow[t]{3}{*}{ Awake } & M & .091 & .131 & -.109 \\
\hline & $\mathrm{F}$ & .019 & .028 & -.006 \\
\hline & All & .055 & .089 & -.049 \\
\hline \multirow[t]{3}{*}{ REM Sleep } & $\mathrm{M}$ & .121 & .308 & .089 \\
\hline & $\mathrm{F}$ & .069 & -.388 & -.091 \\
\hline & All & .066 & .027 & -.013 \\
\hline \multirow[t]{3}{*}{ Light Sleep } & $\mathrm{M}$ & .373 & .414 & .266 \\
\hline & $\mathrm{F}$ & .131 & -.277 & -.154 \\
\hline & All & .262 & .021 & .114 \\
\hline \multirow[t]{3}{*}{ Deep Sleep } & $\mathrm{M}$ & -.091 & -.067 & -.360 \\
\hline & $\mathrm{F}$ & .282 & .000 & -.017 \\
\hline & All & .149 & .004 & -.155 \\
\hline \multirow[t]{3}{*}{ Steps } & $\mathrm{M}$ & .206 & .357 & .026 \\
\hline & $\mathrm{F}$ & -.079 & .351 & -.004 \\
\hline & All & .021 & .292 & -.009 \\
\hline Sedentary & $\mathrm{M}$ & -.273 & -.377 & -.133 \\
\hline
\end{tabular}




\begin{tabular}{|c|c|c|c|c|c|}
\hline & & & & -.369 \\
\hline & & All & -.186 & -.410 & -.240 \\
\hline \multicolumn{2}{|c|}{ Lightly } & $\mathrm{M}$ & .277 & $.457^{*}$ & .101 \\
\hline \multirow{2}{*}{\multicolumn{2}{|c|}{ Active }} & $\mathrm{F}$ & -.003 & $.497 *$ & .002 \\
\hline & & All & .138 & $.445 * *$ & 0.57 \\
\hline \multicolumn{2}{|c|}{ Fairly } & $\mathrm{M}$ & -.143 & .116 & -.133 \\
\hline \multirow{2}{*}{\multicolumn{2}{|c|}{ Active }} & $\mathrm{F}$ & -.092 & .064 & -.092 \\
\hline & & All & -.124 & .087 & -.125 \\
\hline \multicolumn{2}{|c|}{ Very } & $\mathrm{M}$ & .077 & -.031 & -.126 \\
\hline \multirow{2}{*}{\multicolumn{2}{|c|}{ Active }} & $\mathrm{F}$ & -.051 & .067 & .100 \\
\hline & & All & .034 & .013 & -.034 \\
\hline \multicolumn{2}{|c|}{ Activity } & $\mathrm{M}$ & .393 & .090 & .066 \\
\hline \multirow{2}{*}{\multicolumn{2}{|c|}{ Calories }} & $\mathrm{F}$ & .051 & .392 & -.072 \\
\hline & & All & .272 & .160 & .051 \\
\hline \multirow{3}{*}{\multicolumn{2}{|c|}{ Internet use }} & $\mathrm{M}$ & -.426 & -.112 & -.157 \\
\hline & & $\mathrm{F}$ & -.068 & -.156 & -.095 \\
\hline & & All & -.200 & -.036 & -.076 \\
\hline \multicolumn{2}{|c|}{ Productive } & $\mathrm{M}$ & -.172 & .050 & .134 \\
\hline \multicolumn{2}{|c|}{ Internet } & $\mathrm{F}$ & -.062 & -.096 & .033 \\
\hline \multicolumn{2}{|c|}{ Use } & All & -.078 & .058 & .126 \\
\hline \multicolumn{6}{|c|}{$\begin{array}{l}\text { *. Correlation is significant at the } 0.05 \text { level ( } 2 \text {-tailed). } \\
\text { **. Correlation is significant at the } 0.01 \text { level ( } 2 \text {-tailed). } \\
\text { REM: rapid eye movement (one phase of sleep stages); } B E= \\
\text { behavioral engagement; } E E=\text { emotional engagement; } C E=\text { cogni } \\
\text { engagement; }\end{array}$} \\
\hline \multicolumn{6}{|c|}{$\begin{array}{c}\text { Table 5. Pearson correlations between } \\
\text { contextual factors and domains of } \\
\text { engagement in math }\end{array}$} \\
\hline & & $\mathrm{BE}$ & $\mathrm{EE}$ & $\mathrm{CE}$ & $\mathrm{AE}$ \\
\hline \multirow[t]{3}{*}{ Asleep } & $\mathrm{M}$ & .222 & .120 & .373 & .236 \\
\hline & $\mathrm{F}$ & .034 & $-.407^{*}$ & .090 & .053 \\
\hline & All & .058 & -.261 & .105 & .122 \\
\hline \multirow[t]{3}{*}{ Awake } & $\mathrm{M}$ & .277 & .301 & .302 & .405 \\
\hline & $\mathrm{F}$ & -.142 & -.080 & .230 & .187 \\
\hline & All & .077 & .051 & .212 & $.304 *$ \\
\hline REM & $\mathrm{M}$ & .286 & .264 & .348 & .119 \\
\hline \multirow[t]{2}{*}{ Sleep } & $\mathrm{F}$ & -.072 & $-.428 *$ & .121 & -.053 \\
\hline & All & .108 & -.124 & .161 & .052 \\
\hline Light & $\mathrm{M}$ & .031 & .020 & .273 & .249 \\
\hline Sleep & $\mathrm{F}$ & .031 & -.264 & .164 & -.046 \\
\hline & All & .039 & -.074 & .212 & .162 \\
\hline Deep & $\mathrm{M}$ & -.243 & .017 & -.010 & .022 \\
\hline Sleep & $\mathrm{F}$ & -.014 & -.241 & .004 & .063 \\
\hline & All & -.122 & -.088 & .015 & .039 \\
\hline Steps & $\mathrm{M}$ & .193 & .333 & $.437 *$ & .381 \\
\hline & $\mathrm{F}$ & -.351 & .199 & -.201 & .055 \\
\hline & All & -.048 & .168 & .044 & \\
\hline Sedentary & $\mathrm{M}$ & -.147 & -.243 & -.331 & -.361 \\
\hline & $\mathrm{F}$ & .210 & -.114 & -.031 & -.033 \\
\hline & All & -.048 & -.190 & -.194 & -.259 \\
\hline Lightly & $\mathrm{M}$ & .233 & .392 & .419 & $.462 *$ \\
\hline Active & $\mathrm{F}$ & -.387 & .094 & -.171 & .210 \\
\hline & All & .015 & .201 & .108 & $.378 * *$ \\
\hline Fairly & $\mathrm{M}$ & -.126 & -.001 & -.033 & .171 \\
\hline Active & $\mathrm{F}$ & -.391 & -.170 & -.327 & .148 \\
\hline & All & -.217 & -.097 & -.171 & .160 \\
\hline Very & $\mathrm{M}$ & .018 & .153 & .106 & .420 \\
\hline Active & $\mathrm{F}$ & .000 & .226 & -.219 & .182 \\
\hline & All & .020 & .170 & -.025 & $.351^{*}$ \\
\hline Activity & M & .277 & .339 & .350 & $.634 * *$ \\
\hline
\end{tabular}

\begin{tabular}{l|lllll} 
Calories & $\mathrm{F}$ & -.212 & .095 & -.334 & .182 \\
& $\mathrm{All}$ & .198 & .257 & .149 & $.543 * *$ \\
Internet & $\mathrm{M}$ & -.277 & -.273 & -.234 & -.101 \\
use & $\mathrm{F}$ & .095 & -.110 & .117 & -.241 \\
& $\mathrm{All}$ & -.071 & -.057 & .032 & -.176 \\
Productive & $\mathrm{M}$ & -.353 & -.294 & -.312 & -.168 \\
Internet & $\mathrm{F}$ & .138 & .051 & .109 & -.290 \\
use & $\mathrm{Alll}$ & -.118 & .000 & -.011 & .122 \\
\hline *. Correlation is significant at the 0.05 level (2-tailed). \\
**. Correlation is significant at the 0.01 level (2-tailed). \\
REM: rapid eye movement (one phase of sleep stages); BE= \\
behavioral engagement; EE= emotional engagement; CE=cognitive \\
engagement; AE= agentic engagement;
\end{tabular}

\section{Discussions and Conclusions}

This study aims to 1) verify the proposed semiautomated Day Reconstruction Method, and 2) investigate the relationship between contextual factors (Physical exercise, Sleep and Internet use) and domains of school engagement and domains of engagement in math. The proposed semi-automated Day Reconstruction Method is automatic and nonintrusive in capturing the 24-hour physical exercise and sleep data utilizing wearable devices.

The pilot study was conducted and showed the feasibility of using proposed semi-automatic measures to understand adolescents' daily routine. The pilot study also revealed some relationships between the contextual factors and academic engagement. Emotional engagement in school was associated with physical activities and sleep. For the domains of engagement in math, emotional engagement and agentic engagement were associated with physical activities and sleep. These associations were different across gender, which aligns with a previous study on physical activities and educational outcomes [42]. Overall, it can be seen that appropriate amount of exercise is beneficial for students' academic engagement.

Interestingly, the result revealed that "very active" physical activity was only associated with agentic engagement in math. However, the level of being "lightly active" was associated with more domains of engagement. This is contradictory with past research where moderate or vigorous exercises were associated with academic engagement, at least among boys [21][42]. As shown in Table 2, when students were active, the intensity was mostly light. The duration of light activity was nearly five times more than that of moderate activity and four times more than that of vigorous activity. This might be related to the educational context of Hong Kong where physical activities are somewhat discouraged by heavy academic load and small campuses. 
Sleep duration was positively associated with school engagement. However, shorter sleep and more awakenings were associated with higher emotional engagement in math and agentic engagement in math respectively. This might indicate an over-excitement or anxiety over math among some of the students, which consequently affected their sleep. Further studies, especially qualitative ones, are needed to verify this interpretation.

Last but not least, the duration of Internet use was not found to have any significant relationship with any domain of engagement. Previous studies have revealed both positive and negative relationships between Internet use and learning and health outcomes. It was found that using Internet to learn was positively associated with a healthy life [30]. Other studies shows negative impacts of using internet for hedonic purpose on academic performances ([43],[44]). The differences between findings of this study and those of previous studies might be due to the small sample size and the fact that the participants had moderate usage of Internet in general (3.31 hours per day).

In summary, we proposed a new semi-automated Day Reconstruction Method to collect data and measure three contextual factors in students' life world. Through a pilot study on the relationships between these contextual factors and academic engagement, we demonstrated: 1) that the proposed method was feasible to be applied in a classroom setting; and 2) that there were significant correlations between two of these contextual factors (Physical activities and Sleep) and academic engagement (including both general engagement and engagement in Math).

\section{Limitations and Future Work}

This pilot study involved a fairly small sample size, which limits the generalization power of the findings. In the main study to be conducted, a bigger sample size will be recruited. Moreover, for physical activities, this pilot study only involved the duration of physical activities with different intensity levels. In future study, the timing and the frequency of physical activity can also be taken into the reconstruction of daily routine. Similarly, regularity of sleep can also be analyzed in future work.

\section{Acknowledgement}

The author(s) wish to acknowledge that this work is funded by the Research Grants Council of the HKSAR Government, grant \#T44-707/16/N, under the Theme Based Research Scheme.

\section{References}

[1] J. D. Willms, S. Friesen, and P. Milton, What Did You Do in School Today? Transforming Classrooms through Social, Academic, and Intellectual Engagement.(First National Report). ERIC, 2009.

[2] R.-D. Liu et al., "Teacher support and math engagement: roles of academic self-efficacy and positive emotions," Educ. Psychol., vol. 38, no. 1, pp. 3-16, 2017.

[3] H. M. Marks, "Student Engagement in Instructional Activity: Patterns in the Elementary, Middle, and High School Years," Am. Educ. Res. J., vol. 37, no. 1, pp. 153-184, 2000.

[4] E. Husserl, "The Crisis of European Sciences and Transcendental Phenomenology," ... Transcend. Phenomenol., pp. 1-116, 1970.

[5] R. Pianta, B. K. Hamre, and J. P. Allen, Handbook of Research on Student Engagement. 2012.

[6] J. A. Fredricks, P. Blumenfeld, and A. Paris, "School Engagement : Potential of the Concept, State of the Evidence," Rev. Educ. Res., vol. 74, no. 1, pp. 59-109, 2004

[7] J. D. Finn and D. A. Rock, "Academic Success Among Students at Risk for School Failure," no. 2, 1997.

[8] R. Pekrun and L. Linnenbrink-Garcia, "Academic emotions and student engagement," in Handbook of research on student engagement, Springer, 2012, pp. 259-282.

[9] B. J. Zimmerman, "Self-Regulated Learning and Academic Achievement: An Overview," Educ. Psychol., vol. 25, no. 1, pp. 3-17, 1990.

[10] S. D’Mello, B. Lehman, R. Pekrun, and A. Graesser, "Confusion can be beneficial for learning," Learn. Instr., vol. 29, pp. 153-170, 2014.

[11] J. Reeve and C. M. Tseng, "Agency as a fourth aspect of students' engagement during learning activities," Contemp. Educ. Psychol., vol. 36, no. 4, pp. 257-267, 2011.

[12] N. R. Council, Engaging schools: Fostering high school students' motivation to learn. National Academies Press, 2003.

[13] J. A. Fredricks, M. Filsecker, and M. A. Lawson, "Student engagement, Context, And adjustment: Addressing definitional, Measurement, And methodological issues," Learn. Instr., vol. 43, pp. 14, 2016.

[14] J. J. Appleton, S. L. Christenson, and M. J. Furlong, "Student engagement with school: Critical conceptual and methodological issues of the construct," Psychol. Sch., vol. 45, no. 5, pp. 369386, 2008.

[15] A. J. Martin, J. Way, J. Bobis, and J. Anderson, "Exploring the Ups and Downs of Mathematics Engagement in the Middle Years of School," $J$. Early Adolesc., vol. 35, no. 2, pp. 199-244, 2015.

[16] P. Sullivan, J. Mousley, and R. Zevenbergen, "Increasing access to mathematical thinking," Aust. Math. Soc. Gaz., vol. 32, no. 2, pp. 105-109, 2005.

[17] S. V. Bauducco, I. K. Flink, M. Jansson-Fröjmark, and S. J. Linton, "Sleep duration and patterns in 
adolescents: correlates and the role of daily stressors," Sleep Heal., vol. 2, no. 3, pp. 211-218, 2016.

[18] D. W. Beebe, "Cognitive, Behavioral, and Functional Consequences of Inadequate Sleep in Children and Adolescents," Pediatr. Clin. North Am., vol. 58, no. 3, pp. 649-665, 2011.

[19] M. A. Short, M. Gradisar, L. C. Lack, and H. R. Wright, "The impact of sleep on adolescent depressed mood, alertness and academic performance," J. Adolesc., vol. 36, no. 6, pp. 10251033, 2013.

[20] M. Hysing, A. G. Harvey, S. J. Linton, K. G. Askeland, and B. Sivertsen, "Sleep and academic performance in later adolescence: Results from a large population-based study," J. Sleep Res., vol. 25 , no. 3, pp. 318-324, 2016.

[21] K. B. Owen, P. D. Parker, B. Van Zanden, F. MacMillan, T. Astell-Burt, and C. Lonsdale, "Physical Activity and School Engagement in Youth: A Systematic Review and Meta-Analysis," Educ. Psychol., vol. 51, no. 2, pp. 129-145, 2016.

[22] \& C. L. Katherine B. Owen, Philip D. Parker, Thomas Astell-Burt, "Regular Physical Activity and Educational Outcomes in Youth: A Longitudinal Study," Tetrahedron Lett., vol. 30, no. 30, pp. 39433946, 2017.

[23] H. Tamura, T. Nishida, A. Tsuji, and H. Sakakibara, "Association between excessive use of mobile phone and insomnia and depression among Japanese adolescents," Int. J. Environ. Res. Public Health, vol. 14, no. 7, 2017.

[24] O. Bruni, S. Sette, L. Fontanesi, R. Baiocco, F. Laghi, and E. Baumgartner, "Technology use and sleep quality in preadolescence and adolescence," $J$. Clin. Sleep Med., vol. 11, no. 12, pp. 1433-1441, 2015.

[25] X. Mei, Q. Zhou, X. Li, P. Jing, X. Wang, and Z. $\mathrm{Hu}$, "Sleep problems in excessive technology use among adolescent: a systemic review and metaanalysis," Sleep Sci. Pract., vol. 2, no. 1, p. 9, 2018.

[26] L. B. Aker, "Meta-Analysis of Middle School Science Engagement," 2016.

[27] S. W. H. Kwok, P. H. Lee, and R. L. T. Lee, "Smart device use and perceived physical and psychosocial outcomes among Hong Kong adolescents," Int. J. Environ. Res. Public Health, vol. 14, no. 2, 2017.

[28] J. L. Whitlock, J. L. Powers, and J. Eckenrode, "The Internet and Adolescent Self-Injury," Dev. Psychol., vol. 42, no. 3, 2006.

[29] V. C. Brunetti, E. K. O’Loughlin, J. O’Loughlin, E. Constantin, and É. Pigeon, "Screen and nonscreen sedentary behavior and sleep in adolescents," Sleep Heal., vol. 2, no. 4, pp. 335-340, 2016.

[30] L. Wang, J. Luo, W. Gao, and J. Kong, "The effect of Internet use on adolescents' lifestyles: A national survey," Comput. Human Behav., vol. 28, no. 6, pp. 2007-2013, 2012.

[31] E. Diener and L. Tay, "Review of the Day Reconstruction Method (DRM)," Soc. Indic. Res., vol. 116, no. 1, pp. 255-267, 2014.
[32] H. Zhu et al., "Day Re-construction: Understanding How College Students Manage Their Time Through Self-monitoring," Proc. 52nd Hawaii Int. Conf. Syst. Sci., vol. 6, 2019.

[33] B. E. Ainsworth et al., "2011 compendium of physical activities: A second update of codes and MET values," Med. Sci. Sports Exerc., vol. 43, no. 8, pp. 1575-1581, 2011.

[34] E. L. Van Blarigan, S. A. Kenfield, L. Tantum, L. A. Cadmus-Bertram, P. R. Carroll, and J. M. Chan, "The Fitbit One Physical Activity Tracker in Men With Prostate Cancer: Validation Study," JMIR Cancer, vol. 3, no. 1, p. e5, 2017.

[35] M. Vooijs et al., "Validity and usability of low-cost accelerometers for internet-based self-monitoring of physical activity in patients with chronic obstructive pulmonary disease," J. Med. Internet Res., vol. 16, no. 10, p. e14, 2014.

[36] Z. Beattie, A. Pantelopoulos, A. Ghoreyshi, Y. Oyang, A. Statan, and C. Heneghan, "Estimation of sleep stages using cardiac and accelerometer data from a wrist-worn device," in Sleep, 2017, vol. 40, pp. A26-A26.

[37] D. Di Mitri, M. Scheffel, H. Drachsler, D. Börner, S. Ternier, and M. Specht, "Learning pulse," in Proceedings of the Seventh International Learning Analytics \& Knowledge Conference on - LAK '17, 2017.

[38] C. Y. M. Yuen, "Linking life satisfaction with school engagement of secondary students from diverse cultural backgrounds in Hong Kong," Int. $J$. Educ. Res., vol. 77, no. April, pp. 74-82, 2016.

[39] M. Te Wang, J. A. Fredricks, F. Ye, T. L. Hofkens, and J. S. Linn, "The Math and Science Engagement Scales: Scale development, Validation, And psychometric properties," Learn. Instr., vol. 43, pp. 16-26, 2016.

[40] J. Zhao, L. Lin, J. Sun, X. Zheng, and J. Yin, "Students' engagement in a science classroom: Does knowledge diversity matter?," J. Educ. Res., vol. 111, no. 6, pp. 756-763, 2018.

[41] J. A. D. Datu, W. Yang, J. P. M. Valdez, and S. K. W. Chu, "Is facebook involvement associated with academic engagement among Filipino university students? A cross-sectional study," Comput. Educ., vol. 125, no. March 2017, pp. 246-253, 2018.

[42] K. B. Owen, P. D. Parker, T. Astell-Burt, and C. Lonsdale, "Regular Physical Activity and Educational Outcomes in Youth: A Longitudinal Study," J. Adolesc. Heal., vol. 62, no. 3, pp. 334 340, 2018.

[43] H. Qahri-Saremi and O. Turel, "School engagement, information technology use, and educational development: An empirical investigation of adolescents," Comput. Educ., vol. 102, pp. 65-78, 2016.

[44] L. Vernon, B. L. Barber, and K. L. Modecki, "Adolescent Problematic Social Networking and School Experiences: The Mediating Effects of Sleep Disruptions and Sleep Quality," Cyberpsychology, Behav. Soc. Netw., vol. 18, pp. 386-392, 2015. 
Page 3365 